\title{
Synthesis, characterization, antibacterial evaluation and molecular docking studies of 2-azetidinone derivatives as novel DNA gyrase inhibitors
}

\author{
R. Munavar Sulthana, S. Darlin Quine* \\ Department of Chemistry, Government Arts College, Chidambaram - 608102, India \\ *E-mail address: darlinquine@gmail.com
}

\begin{abstract}
Newly designed 2-azetidinone derivatives (4a-e) were synthesized in good yields and characterised by advanced spectroscopic studies. The title compounds were evaluated for qualitative (zone of inhibition) by agar diffusion method against Staphylococcus aureus, Bacillus subtilis, Escherichia coli, Pseudomonas aeruginosa and Streptococcus pyogenes. Some of the analogues were found to have comparable or even more potency than the standard drugs. Docking study was performed to check interaction of synthesized compounds with the target DNA gyrase.
\end{abstract}

Keywords: Hydrazone; 2-azetidinone; Antibacterial activity; docking; DNA gyrase

\section{INTRODUCTION}

Increasing number of multi-drug resistant microbial pathogens and emerging infectious diseases are the major challenging problems for the clinicians. There is an urgent need to develop new class of potent antimicrobial agents. Heterocyclic compounds play an important role in designing of a new class of structural entities of medicinal importance with new mechanisms of action (Sumit Bansal et al, 2014). The most widely used antibiotics such as the penicillins, cephalosporins, carumonam, aztreonam, thienamycine and the nocardicins all contain $\beta$ - lactam rings3. Biological activity of these heterocycles has helped the medicinal chemist to plan, organize and implement newer approaches towards the discovery of newer drugs. The most widely used antibiotics such as the penicillins, cephalosporins, carumonam, aztreonam, thienamycine and the nocardicins all contain $\beta$ - lactam rings3. Biological activity of these heterocycles has helped the medicinal chemist to plan, organize and implement newer approaches towards the discovery of newer drugs (Kilarimath Basavaraj et al, 2014). In view of the general observation that pharmacological activity is invariably associated with a large variety of heterocyclic compounds, the investigation of some heterocycles such as azetidinone derivatives has been undertaken. 2-Azetidinones, commonly known as b-lactams are well-known heterocyclic compounds among organic and medicinal chemists. The 2 -azetidinone derivatives have been reported to possess wide range of biological activities like antibacterial (Sharma et al., 1998), antifungal (Halve et al., 2007), anti-inflammatory (Gurupadayya et al., 2008), anticonvulsant (Rajasekaran and Murugesan, 2005). Recently, it has been reported that $\beta$-lactams have novel biological activities such as cytomegalovirus protease inhibitors (Kallappa M. Hosamani et al, 2009) and as inhibitors of acyl-CoA cholesterol acyltransferase (Rosenblum et 
al, 2000). The $\beta$-lactams also serve as synthons for many biologically important classes of organic Compounds (Jyotsna Meshram et al, 2010).

The present investigation deals with the clinically isolated different gram positive and gram negative bacteria against synthesized compounds and most of the tested compounds act as potent antibacterial agents. To understand the interactions of tested compounds at active sites of protein receptors, topoisomerase II DNA gyrase enzymes (PDB ID. 2XCT) molecular docking studies were also preformed and reported in this article. DNA gyrase is a major bacterial protein that is involved in replication \&transcription and catalyzes the negative supercoiling of bacterial circular DNA. The enzyme consists of two subunits, A and B, of molecular mass 97 and $90 \mathrm{kDa}$, respectively, with the active enzyme being an A2B2 complex. The A subunit of DNA gyrase is involved in DNA breakage and reunion while the B subunit catalyzes the hydrolysis of ATP(Amit Poshiya et al, 2011). The DNA gyrase is a known target for antibacterial agents since its blocking induces bacterial death. Hence, the studies are further extended to check probable interactions with this mostly preferred bacterial target(Smita pawar et al, 2014).

The main objective of this paper is an approach of designing gyrase inhibitor molecules and their derivatives by docking simulations, followed by the synthesis, characterization and antibacterial evaluation was carried out.

\section{MATERIALS AND METHODS}

All the chemicals and solvents used were of AR grade obtained from Sigma Aldrich, Lobachemie (India). Melting points of the synthesized compounds were determined in openglass on a Staurt-SMP10 melting point apparatus and recorded in ${ }^{\circ} 0 \mathrm{C}$ without correction. The purity of the compounds was ascertained by thin layer chromatography on silica gel coated aluminum plates (Merck) as adsorbent and UV light as visualizing agent. Synthesized compounds were recrystallised using ethanol as solvent. IR spectra were recorded on SHIMADZU FT-IR spectrometer using $\mathrm{KBr}$ pellet technique. ${ }^{1} \mathrm{H}-\mathrm{NMR}$ spectra were recorded on BRUKER-400 spectrometer operating at $400 \mathrm{MH}_{\mathrm{Z}}$ using TMS as internal standard in DMSO (chemical shifts in ppm). Protein Structure Preparation The X-ray crystal structures DNA gyrase (PDB: 3U2D) retrieved from the Research Collaboratory for Structural Bioinformatics (RCSB) Protein Data Bank (Figure 1) was used in this study. Water molecules of crystallization were detached from the composite and the protein was optimized for docking using the protein preparation and refinement utility provided by Schrödinger LLC. Partial atomic charges were assigned according to the OPLS-AA force field.

\section{RESULTS AND DISCUSSIONS}

\subsection{CHEMISTRY}

\subsubsection{General procedure for the synthesis of compounds 3a-e}

In a $250 \mathrm{ml}$ round bottom flask, a mixture of substituted carboxylic acid $(0.1 \mathrm{~mol})$, ethanol (60 $\mathrm{ml})$ and conc. $\mathrm{H}_{2} \mathrm{SO}_{4}(1.4 \mathrm{ml})$ were refluxed for 10 hours on a water bath. The solution was cooled and poured slowly with stirring on to $200 \mathrm{~g}$ of crushed ice. Sufficient ammonia solution was added to render the resulting solution alkaline, generally some ester separates as oil but most of it remains dissolved in the alkaline solution. The solution was extracted five times with ether $(25 \mathrm{ml})$ the combined ethereal extract was dried with anhydrous $\mathrm{MgSO}_{4}$. Ether was removed by 
evaporation on a water bath and the residue was collected. Physical data of ester was noted. The Synthetic procedure is shown in scheme 1.

\subsubsection{General procedure for the synthesis of compounds $4 a-e^{27}$}

A mixture of ester and hydrazine hydrate in 1:1 portion and ethanol $(30 \mathrm{ml})$ were taken in a round bottom flask and refluxed for 4-6 hrs. Excess of ethanol was removed by distillation. On cooling the product, acid hydrazide separates out. It was filtered and collected. Recrystallization was carried out with ethanol and physical data was noted. The physical properties of synthesized derivatives 3(a-e) are shown in Table 1.

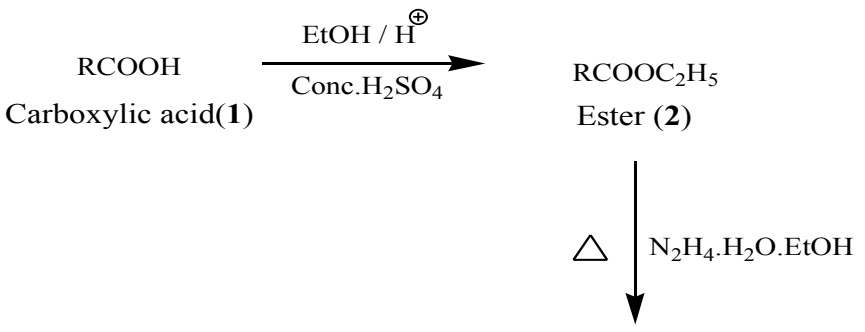

$$
\begin{aligned}
& \mathrm{RCONHNH}_{2} \\
& \text { Acid hydrazide 3(a-e) }
\end{aligned}
$$
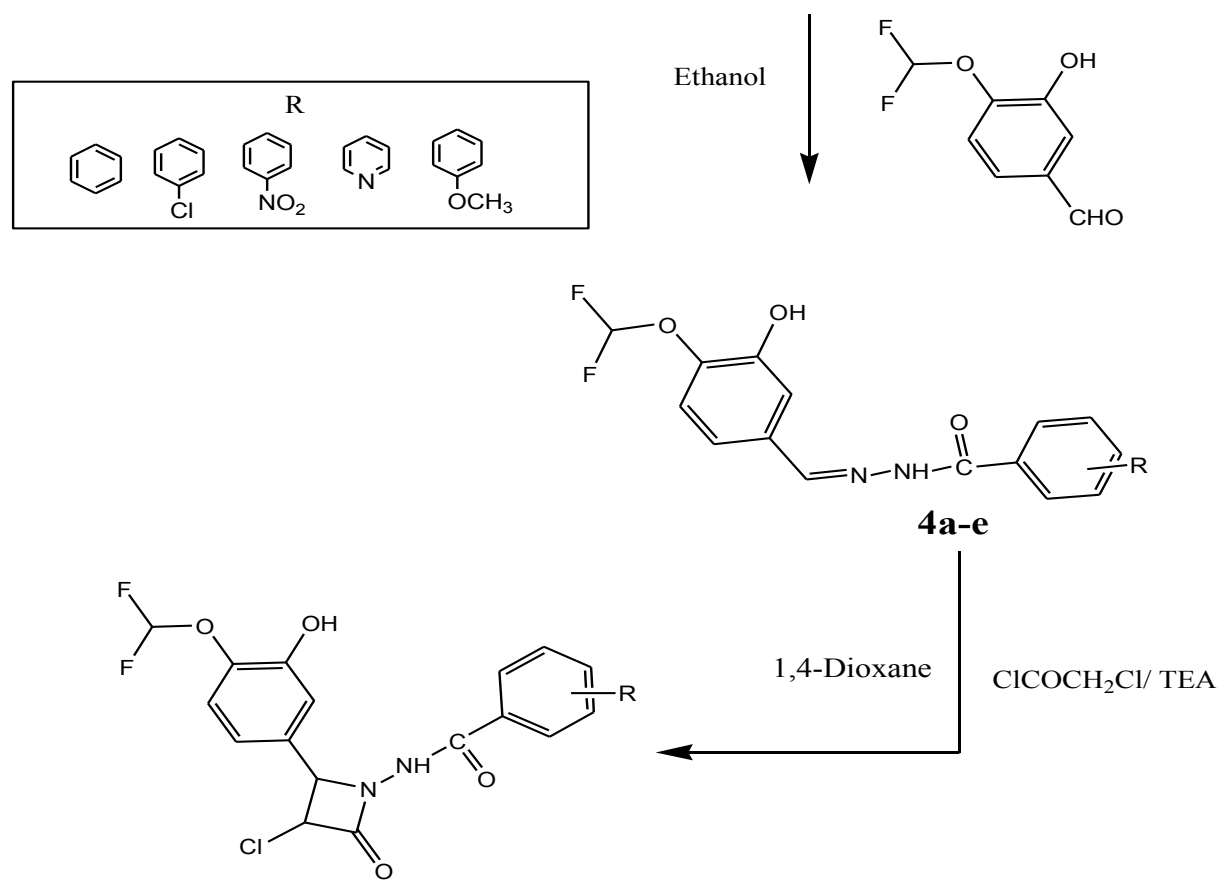

5(a-e)

Scheme 1. Synthesis of the 2-Azetidinone derivatives 5(a-e). 


\subsubsection{Synthesis of $N^{\prime}$-(4-(difluoromethoxy)-3-hydroxybenzylidene)benzohydrazide (4a)}

This was prepared and purified as per the above mentioned procedure: M.F: $\mathrm{C}_{15} \mathrm{H}_{12} \mathrm{~F}_{2} \mathrm{~N}_{2} \mathrm{O}_{3}$; M.Wt:306; yield 67\%, mp 142-146 ${ }^{0} \mathrm{C}$; IR (KBr, m, $\mathrm{cm}^{-1}$ ): 2908 (-Ali CH), 3030 (-Aro CH), $1562(-\mathrm{CH}=\mathrm{N}), 1687(-\mathrm{C}=\mathrm{O}), 3197(-\mathrm{OH})$ and $1172(-\mathrm{C}-\mathrm{F})$;1HNMR: (DMSO-d6, $400 \mathrm{MHz}), \delta$ $8.37(\mathrm{~s}, 1 \mathrm{H}, \mathrm{CH}=\mathrm{N}), \delta 7.12(\mathrm{~s}, 1 \mathrm{H},-\mathrm{NH}), \delta 6.93(\mathrm{~s}, 1 \mathrm{H},-\mathrm{OH}), \delta 7.30\left(\mathrm{~s}, 1 \mathrm{H},-\mathrm{CHF}_{2}\right)$ and $\delta 7.12-$ $7.92(\mathrm{~m}, 8 \mathrm{H}$, Aromatic protons)

\subsubsection{Synthesis of N'-(4-(difluoromethoxy)-3-hydroxybenzylidene)-4-chlorobenzohydrazide} (4b)

This was prepared and purified as per the above mentioned procedure: M.F: $\mathrm{C}_{15} \mathrm{H}_{11} \mathrm{ClF}_{2} \mathrm{~N}_{2} \mathrm{O}_{3}$; M.Wt:340; yield 72\%, mp 115-117 ${ }^{0} \mathrm{C}$; IR (KBr, m, cm ${ }^{-1}$ ): 2960 (-Ali CH), 3134(-Aro CH), $1598(-\mathrm{CH}=\mathrm{N}), 1637 \quad(-\mathrm{C}=\mathrm{O}), 3317(-\mathrm{OH}), 1109(-\mathrm{C}-\mathrm{F})$ and 750 (-CCl);1HNMR: (DMSO-d6, $400 \mathrm{MHz}), \delta 8.30(\mathrm{~s}, 1 \mathrm{H}, \mathrm{CH}=\mathrm{N}), \delta 7.00(\mathrm{~s}, 1 \mathrm{H},-\mathrm{NH}), \delta 6.89$ (s, $1 \mathrm{H}$, $\mathrm{OH}), \delta 7.19\left(\mathrm{~s}, 1 \mathrm{H},-\mathrm{CHF}_{2}\right)$ and $\delta$ 7.07-7.90 (m, 7H, Aromatic protons).

\subsubsection{Synthesis of $N^{\prime}$-(4-(difluoromethoxy)-3-hydroxybenzylidene)-4-nitrobenzohydrazide}

(4c)

This was prepared and purified as per the above mentioned procedure: M.F: $\mathrm{C}_{15} \mathrm{H}_{11} \mathrm{~F}_{2} \mathrm{~N}_{3} \mathrm{O}_{5}$; M.Wt:351; yield 65\%, mp 110-112 ${ }^{0} \mathrm{C}$; IR (KBr, m, $\mathrm{cm}^{-1}$ ): 2931 (-Ali $\mathrm{CH}$ ), 3062 (-Aro CH), $1589(-\mathrm{CH}=\mathrm{N}), 1687(-\mathrm{C}=\mathrm{O}), 3304(-\mathrm{OH})$ and $1128(-\mathrm{C}-\mathrm{F}$; 1HNMR: (DMSO-d6, $400 \mathrm{MHz}), \delta$ $8.36(\mathrm{~s}, 1 \mathrm{H}, \mathrm{CH}=\mathrm{N}), \delta 7.04(\mathrm{~s}, 1 \mathrm{H},-\mathrm{NH}), \delta 6.94(\mathrm{~s}, 1 \mathrm{H},-\mathrm{OH}), \delta 7.23\left(\mathrm{~s}, 1 \mathrm{H},-\mathrm{CHF}_{2}\right)$ and $\delta 7.04-$ 8.15 ( $\mathrm{m}, 7 \mathrm{H}$, Aromatic protons)

\subsubsection{Synthesis of $N^{\prime}$-(4-(difluoromethoxy)-3-hydroxybenzylidene)isonicotinohydrazide}

(4d)

This was prepared and purified as per the above mentioned procedure: M.F: $\mathrm{C}_{14} \mathrm{H}_{11} \mathrm{~F}_{2} \mathrm{~N}_{3} \mathrm{O}_{3}$; M.Wt:307; yield 68\%, mp 124-126 ${ }^{\circ} \mathrm{C}$; IR (KBr, m, $\mathrm{cm}^{-1}$ ): 2912 (-Ali CH), 3035 (-Aro CH), $1568(-\mathrm{CH}=\mathrm{N}), 1645(-\mathrm{C}=\mathrm{O}), 3288(-\mathrm{OH})$ and $1170(-\mathrm{C}-\mathrm{F})$;1HNMR: (DMSO-d6, $400 \mathrm{MHz}), \delta$ $8.34(\mathrm{~s}, 1 \mathrm{H}, \mathrm{CH}=\mathrm{N}), \delta 7.11(\mathrm{~s}, 1 \mathrm{H},-\mathrm{NH}), \delta 6.93(\mathrm{~s}, 1 \mathrm{H},-\mathrm{OH}), \delta 7.30\left(\mathrm{~s}, 1 \mathrm{H},-\mathrm{CHF}_{2}\right)$ and $\delta 7.14-$ 8.77 ( $\mathrm{m}, 7 \mathrm{H}$, Aromatic protons)

\subsubsection{Synthesis of $N^{\prime}$-(4-(difluoromethoxy)-3-hydroxybenzylidene)-4- methoxybenzohydrazide (4e)}

This was prepared and purified as per the above mentioned procedure: M.F: $\mathrm{C}_{16} \mathrm{H}_{14} \mathrm{~F}_{2} \mathrm{~N}_{2} \mathrm{O}_{4}$; M.Wt:336; yield 75\%, mp 135-137 ${ }^{\circ} \mathrm{C}$; IR (KBr, m, $\mathrm{cm}^{-1}$ ): 2931 (-Ali CH), 3053 (-Aro CH), $1591(-\mathrm{CH}=\mathrm{N}), 1687(-\mathrm{C}=\mathrm{O}), 3329(-\mathrm{OH})$ and $1130(-\mathrm{C}-\mathrm{F})$;1HNMR: (DMSO-d6, $400 \mathrm{MHz}), \delta$ $8.33(\mathrm{~s}, 1 \mathrm{H}, \mathrm{CH}=\mathrm{N}), \delta 7.05(\mathrm{~s}, 1 \mathrm{H},-\mathrm{NH}), \delta 6.91(\mathrm{~s}, 1 \mathrm{H},-\mathrm{OH}), \delta 7.42\left(\mathrm{~s}, 1 \mathrm{H},-\mathrm{CHF}_{2}\right), \delta 3.83(\mathrm{~s}$, $\left.3 \mathrm{H},-\mathrm{OCH}_{3}\right)$ and $\delta 7.04-7.91(\mathrm{~m}, 7 \mathrm{H}$, Aromatic protons) 


\subsection{General procedure for the synthesis of compounds (5a-e)}

Hydrazones 3a-f $(0.04 \mathrm{~mol})$ and triethylamine $(0.02 \mathrm{~mol})$ in dioxan $(20 \mathrm{~mL})$ at $0-5^{\circ} \mathrm{C}$ mixture was stirred for $5 \mathrm{~h}$. During stirring, chloroacetyl chloride $(0.01 \mathrm{~mol})$ in dioxan $(10 \mathrm{~mL})$ was added dropwise. The mixture was refluxed for $2 \mathrm{~h}$ and kept for two days on room temperature.

Table 1. Physical properties and IR Spectral Data of Synthesized Hydrazides 3(a-e).

\begin{tabular}{|c|c|c|c|c|c|c|}
\hline Compound & $\mathrm{R}$ & $\begin{array}{l}\text { Molecular } \\
\text { formula }\end{array}$ & $\begin{array}{l}\text { M.Pt } \\
\left({ }^{\circ} \mathrm{C}\right)\end{array}$ & $\begin{array}{c}\text { M. } \\
\text { Formula }\end{array}$ & $\begin{array}{l}\text { Physical } \\
\text { state }\end{array}$ & IR Frequency \\
\hline $3 a$ & $\mathrm{C}_{6} \mathrm{H}_{5}$ & $\mathrm{C}_{7} \mathrm{H}_{8} \mathrm{~N}_{2} \mathrm{O}$ & 110 & 136 & $\begin{array}{l}\text { White } \\
\text { powder }\end{array}$ & $\begin{array}{c}3032 \mathrm{~cm}^{-1} \\
(\mathrm{C}-\mathrm{H} \mathrm{Ar} \mathrm{str}) ; 1622 \mathrm{~cm}^{-1} \\
(\mathrm{C}=\mathrm{O} \text { str); } 3296,3215 \\
\left.\text { (NHNH } \mathrm{NH}_{2} \mathrm{str}\right) ; 985 \mathrm{~cm}^{-1} \\
\text { (N-N str). }\end{array}$ \\
\hline $3 b$ & $\mathrm{C}_{6} \mathrm{H}_{5} \mathrm{Cl}$ & $\mathrm{C}_{7} \mathrm{H}_{7} \mathrm{ClN}_{2} \mathrm{O}$ & 162 & 170 & $\begin{array}{l}\text { White } \\
\text { powder }\end{array}$ & $\begin{array}{c}3016 \mathrm{~cm}^{-1} \\
(\mathrm{C}-\mathrm{H} \mathrm{Ar} \mathrm{str}) ; \\
1645 \mathrm{~cm}^{-1}(\mathrm{C}=\mathrm{O} \mathrm{str}) ; 3302, \\
3209 \mathrm{~cm}^{-1} \\
\left(\mathrm{NHNH}_{2} \mathrm{str}\right) ; 727 \mathrm{~cm}^{-1} \\
(\mathrm{C}-\mathrm{Cl} \mathrm{str}) ; 987 \mathrm{~cm}^{-1} \\
\text { (N-N str). }\end{array}$ \\
\hline $3 \mathrm{c}$ & $\begin{array}{c}\mathrm{C}_{6} \mathrm{H}_{5} \mathrm{~N} \\
\mathrm{O}_{2}\end{array}$ & $\mathrm{C}_{7} \mathrm{H}_{7} \mathrm{~N}_{3} \mathrm{O}_{3}$ & 215 & 181 & $\begin{array}{l}\text { Pale Yellow } \\
\text { powder }\end{array}$ & $\begin{array}{c}3070 \mathrm{~cm}^{-1} \\
(\mathrm{C}-\mathrm{H} \mathrm{Ar} \mathrm{str}) ; \\
1662 \mathrm{~cm}^{-1}(\mathrm{C}=\mathrm{O} \mathrm{str}) ; \\
3296,3180 \mathrm{~cm}^{-1} \\
\left(\mathrm{NHNH}_{2} \mathrm{str}\right) ; 1525 \mathrm{~cm}^{-1} \\
\left(\mathrm{NO}_{2} \mathrm{str}\right) ; 1055 \mathrm{~cm}^{-1}(\mathrm{~N}-\mathrm{N} \\
\text { str }) .\end{array}$ \\
\hline $3 d$ & $\mathrm{C}_{5} \mathrm{H}_{5} \mathrm{~N}$ & $\mathrm{C}_{6} \mathrm{H}_{7} \mathrm{~N}_{3} \mathrm{O}$ & 170 & 137 & $\begin{array}{l}\text { White } \\
\text { powder }\end{array}$ & $\begin{array}{c}3064 \mathrm{~cm}^{-1} \\
(\mathrm{C}-\mathrm{H} \mathrm{Ar} \mathrm{str}) ; 1649 \mathrm{~cm}^{-1} \\
(\mathrm{C}=\mathrm{O} \mathrm{str}) ; 3305 \\
3178 \mathrm{~cm}^{-1} \\
\left(\mathrm{NHNH}_{2} \mathrm{str}\right) ; 1045 \mathrm{~cm}^{-1} \\
\text { (N-N str). }\end{array}$ \\
\hline $3 e$ & $\begin{array}{c}\mathrm{C}_{6} \mathrm{H}_{5} \mathrm{O} \\
\mathrm{CH}_{3}\end{array}$ & $\mathrm{C}_{8} \mathrm{H}_{10} \mathrm{~N}_{2} \mathrm{O}_{2}$ & 135 & 166 & $\begin{array}{l}\text { White } \\
\text { powder }\end{array}$ & $\begin{array}{c}3043 \mathrm{~cm}^{-1} \\
\left(\mathrm{C}-\mathrm{H} \text { Ar str)} ; 2933 \mathrm{~cm}^{-1}\right. \\
(\mathrm{C}-\mathrm{H} \text { Aliphatic str); } 1612 \\
\mathrm{cm}^{-1}(\mathrm{C}=\mathrm{O} \text { str }) ; 3381 \\
3253 \mathrm{~cm}^{-1}\left(\mathrm{NHNH} \mathrm{str}_{2}\right) \\
1031 \mathrm{~cm}^{-1} \text { (N-N str). }\end{array}$ \\
\hline
\end{tabular}

The resulting mixture was poured in the water and the solid was separated out. Recrystallization was done with ethanol-water or chloroform- water to give the azetidine-2-one, 4a-f compounds. 


\subsubsection{Synthesis of $\mathrm{N}$-(3-chloro-2-(4-(difluoromethoxy)-3-hydroxyphenyl)-4-oxoazetidin-1-} yl) benzamide (5a)

This was prepared and purified as per the above mentioned procedure: M.F: $\mathrm{C}_{17} \mathrm{H}_{13} \mathrm{ClF}_{2} \mathrm{~N}_{2} \mathrm{O}_{4}$; M.Wt:382; yield 64\%, mp 208-210 ${ }^{0} \mathrm{C}$; IR (KBr, m, cm ${ }^{-1}$ ): 2926 (-Ali CH), 3051 (-Aro CH), $1681(-\mathrm{C}=\mathrm{O}), 3425(-\mathrm{OH}) ; 1 \mathrm{H}$ NMR (400 MHz, DMSO-d6) (ppm): 4.83(d, 1H, $-\mathrm{CH}-\mathrm{N}), 9.73(\mathrm{~d}, 1 \mathrm{H}, \mathrm{OH}), 4.53(\mathrm{~d}, 1 \mathrm{H},-\mathrm{CH}-\mathrm{Cl})$ 7.09-8.04 (m, 4H, Ar-H)

\subsubsection{Synthesis of 4-chloro-N-(3-chloro-2-(4-(difluoromethoxy)-3-hydroxyphenyl)-4- oxoazetidin-1-yl)benzamide (5b)}

This was prepared and purified as per the above mentioned procedure: M.F: $\mathrm{C}_{17} \mathrm{H}_{12} \mathrm{C}_{12} \mathrm{~F}_{2} \mathrm{~N}_{2} \mathrm{O}_{4}$; M.Wt:417; yield : 60\%, mp 235-237 ${ }^{0} \mathrm{C}$; IR (KBr, m, cm ${ }^{-1}$ ): 2920 (-Ali CH), 3047 (-Aro CH), 1664 (-C=O), 3435 (-OH); 1H NMR (400 MHz, DMSO-d6) (ppm): 4.62(d, 1H, $-\mathrm{CH}-\mathrm{N}), 9.89(\mathrm{~s}, 1 \mathrm{H}, \mathrm{OH}), 4.48(\mathrm{~d}, 1 \mathrm{H},-\mathrm{CH}-\mathrm{Cl}) 6.86-7.82(\mathrm{~m}, 4 \mathrm{H}, \mathrm{Ar}-\mathrm{H})$

\subsubsection{Synthesis of N-(3-chloro-2-(4-(difluoromethoxy)-3-hydroxyphenyl)-4-oxoazetidin-1- yl)-4-nitrobenzamide (5c)}

This was prepared and purified as per the above mentioned procedure: M.F: $\mathrm{C}_{17} \mathrm{H}_{12} \mathrm{ClF}_{2} \mathrm{~N}_{3} \mathrm{O}_{6}$; M.Wt:427; yield : 56\%, mp 240-242 ${ }^{0} \mathrm{C}$; IR (KBr, m, cm $\left.{ }^{-1}\right): 2926$ (-Ali CH), 3051 (-Aro CH), 1664 (-C=O), $3431(-\mathrm{OH}) ; 1 \mathrm{H}$ NMR (400 MHz, DMSO-d6) (ppm): 4.37(d, 1H, $-\mathrm{CH}-\mathrm{N}), 11.89$ (s, 1H, OH), $4.14(\mathrm{~d}, 1 \mathrm{H},-\mathrm{CH}-\mathrm{Cl})$ 7.16-8.35 (m, 4H, Ar-H)

\subsubsection{Synthesis of N-(3-chloro-2-(4-(difluoromethoxy)-3-hydroxyphenyl)-4-oxoazetidin-1- yl)isonicotinamide (5d)}

This was prepared and purified as per the above mentioned procedure: M.F: $\mathrm{C}_{16} \mathrm{H}_{12} \mathrm{ClF}_{2} \mathrm{~N}_{3} \mathrm{O}_{4}$; M.Wt:383; yield : 65\%, mp 210-212 ${ }^{\circ} \mathrm{C}$; IR (KBr, m, cm ${ }^{-1}$ ): 2924 (-Ali CH), 3045 (-Aro CH), 1674 (-C=O), 3425 (-OH); 1H NMR (400 MHz, DMSO-d6) (ppm): 4.77 (d, $1 \mathrm{H},-\mathrm{CH}-\mathrm{N}), 11.84$ (s, 1H, OH), $4.72(\mathrm{~d}, 1 \mathrm{H},-\mathrm{CH}-\mathrm{Cl})$ 6.56-8.35 (m, 4H, Ar-H)

\subsubsection{Synthesis of N-(3-chloro-2-(4-(difluoromethoxy)-3-hydroxyphenyl)-4-oxoazetidin-1- yl)-4-methoxybenzamide (5e)}

This was prepared and purified as per the above mentioned procedure: M.F: $\mathrm{C}_{18} \mathrm{H}_{15} \mathrm{ClF}_{2} \mathrm{~N}_{2} \mathrm{O}_{5}$; M.Wt:412; yield : 60\%, mp 182-184 ${ }^{0} \mathrm{C}$; IR (KBr, m, cm ${ }^{-1}$ ): 2927 (-Ali CH), 3043 (-Aro CH), 1672 (-C=O), 3425 (-OH); 1H NMR (400 MHz, DMSO-d6) (ppm): 4.78(d, 1H, $-\mathrm{CH}-\mathrm{N}), 11.69$ (s, 1H, OH), 4.69 (d, 1H, $-\mathrm{CH}-\mathrm{Cl})$ 6.91-7.91 (m, 4H, Ar-H)

\subsection{MOLECULAR DOCKING STUDIES}

\subsubsection{Ligand Structure Preparation}

The ligand structures were constructed using the splinter dictionary of Maestro 9.3 (Schrodinger, LLC) using the Optimized Potentials for Liquid Simulations-All Atom (OPLSAA) force field with the steepest descent followed by curtailed Newton conjugate gradient 
protocol. Partial tomic charges were computed using the OPLS-AA force field(Pandurangan Perumal).

\subsubsection{Docking Protocol}

All docking calculations were performed using the "Extra Precision" (XP) mode of GLIDE program. The binding site, for which the various energy grids were designed and stored, was defined in terms of two concentric cubes: the bounding box, which must contain the center of any acceptable ligand pose and enclosing box. It must include all ligand atoms of an acceptable pose, with a Root Mean Square Deviation (RMSD) smaller amount than $0.5 \AA$ and an utmost atomic dislocation of less than $1.3 \AA$ were eliminated as an outmoded in order to increase diversity in the retained ligand poses. The scale factor for van der Waals radii was applied to those atoms with absolute partial charges less than or unchanged to 0.15 (scale factor of 0.8 ) and 0.25 (scale factor of 1.0) electrons for ligand and protein, correspondingly. The max keep variable which sets the maximum number of poses generated during the initial phase docking calculation were set to 5000 and the keep best variable which sets the number of poses per ligand that enters the energy minimization was set to 1000

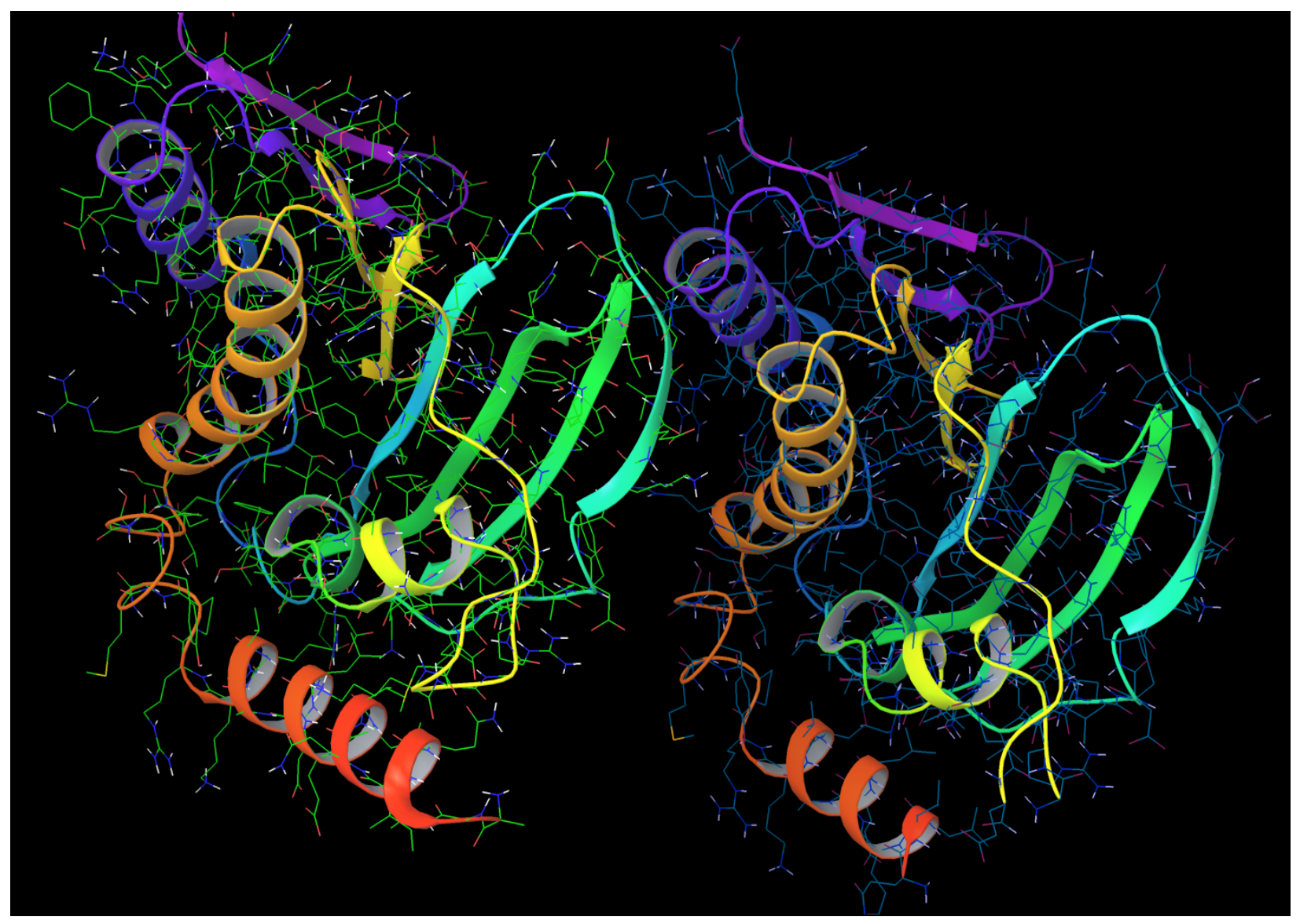

Figure 1. X-ray crystal structure of protein DNA gyrase (PDB: 3U2D). 
Energy minimization protocol includes dielectric constant of 4.0 and 1000 conjugate gradient steps. Upon completion of each docking calculation, at most 100 poses per ligand were generated. The paramount docked structure was chosen using a GLIDE score (Gscore) function. One more scoring function used by GLIDE E-model, which itself consequent from a combination of the Gscore, Columbic, van der Waals and the strain energy of the ligand.

\subsubsection{Qikprop Analysis}

Qikprop efficiently evaluates pharmaceutically relevant properties for over half a million compounds per hour, making it a vital lead creation and lead optimization implement. Accurate prediction of Absorption, Distribution, Metabolism, Elimination (ADME) properties prior to expensive experimental procedures, such as High Throughput Screening (HTS), can eliminate unnecessary testing on compounds that will ultimately fail; ADME prediction can also be used to focus lead optimization efforts to enhance the desired properties of a given compound.

Table 2. Molecular docking studies of synthesized 2-Azetidinone Derivatives 5(a-e) compounds.

\begin{tabular}{|c|c|c|c|}
\hline S.No & Compound & Glide Score & Glide Energy \\
\hline 1 & $5 \mathrm{a}$ & -5.918678 & -39.383112 \\
\hline 2 & $5 \mathrm{~b}$ & -6.467631 & -42.172485 \\
\hline 3 & $5 \mathrm{c}$ & -6.018386 & -45.487493 \\
\hline 4 & $5 \mathrm{~d}$ & -6.064761 & -43.744902 \\
\hline 5 & $5 \mathrm{e}$ & -6.396769 & -40.713267 \\
\hline 7 & Ciprofloxacin & -7.636035 & -30.0573 \\
\hline
\end{tabular}

Considering the well obtained in vitro results, it was thought worthy to perform molecular docking studies, hence screening the compounds, inculcating both in silico and in vitro results. Considering DNA gyrase as the target receptor, comparative and automated docking studies with newly synthesized compounds was performed to determine the best in silico conformation. Fig. 1 shows the native crystal structure of DNA gyrase was obtained from Protein Data Bank (http://www.pdb.org/pdb/home/home.do) with the PDB ID 3U2D.

The active pocket consisted of amino acid residues as LEU 103, VAL 131, $79 \& 130$, ILE 51, 86, $102 \&$ 175, THR 173,SER 55, \& 129, ASP 81, ASN 54, GLU 58, GLY 83 \& 85, PRO 87 and ARG $84 \& 144$ as shown in Fig. 3. The synthesized ligand molecules having 2D structure were converted to energy minimized 3D structures and were further used for in silico protein-ligand docking. All the five synthesized molecules ( 5a-e) were docked. Fig.2 shows the 


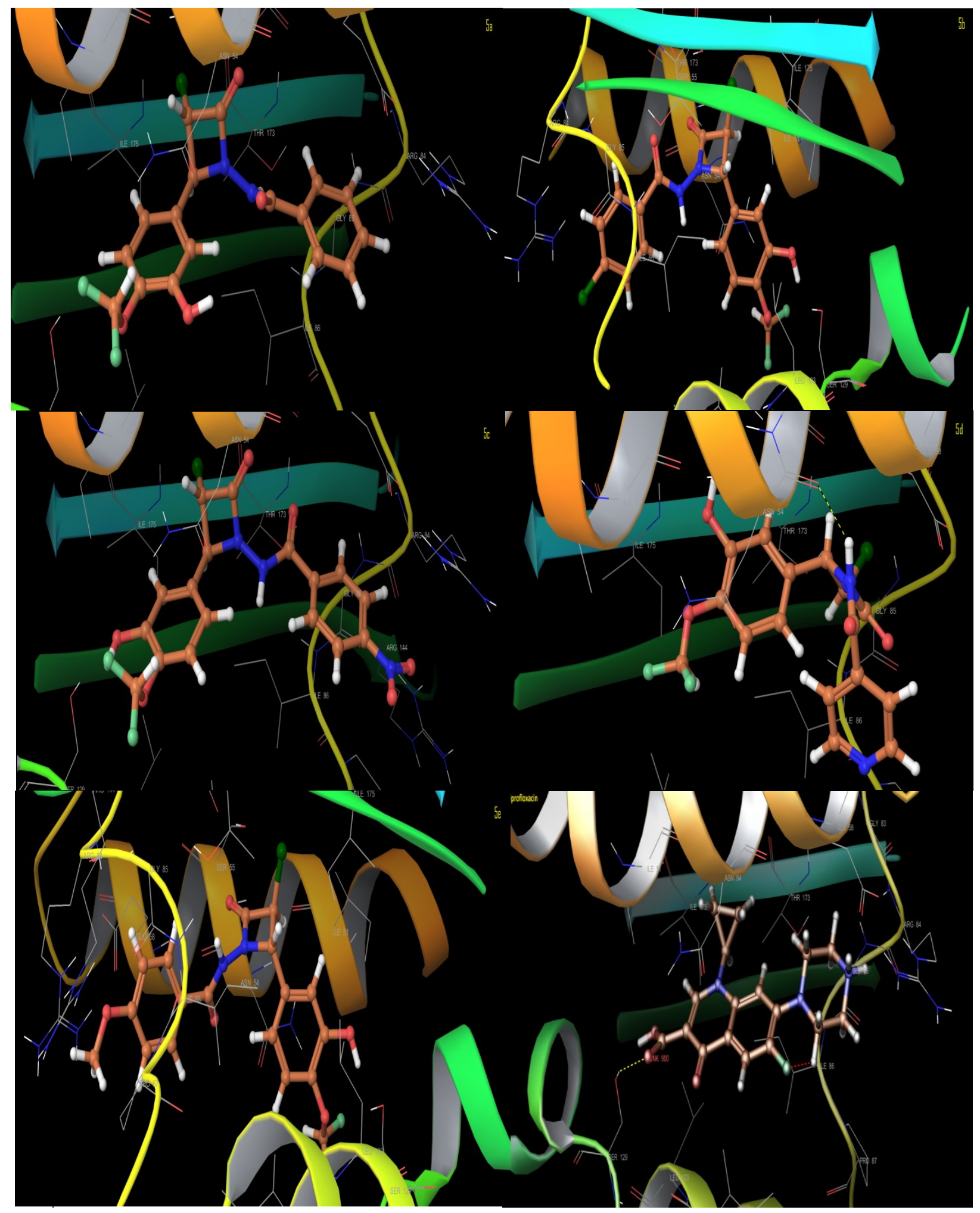

Figure 2. Docking of synthesized azetidinone derivatives (5a-e) with reference standard ciprofloxacin into the active site of DNA gyrase. The amino acids involved in hydrogen, hydrophobic and van der Waals interactions are highlighted. 
docked images of selected ligands including the considered standard drug i.e. ciprofloxacin. Table 2 shows the Binding Energy and glide score of six compounds including the standard. In silico studies revealed all the synthesized molecules showed good binding energy toward the target protein ranging from

Derivatives $5 \mathrm{a}, 5 \mathrm{~b}$ and $5 \mathrm{e}$ shows hydrophobic intractions with the active site of gyrase (Fig. 3). Energy scores (S) and docking scores for compounds 5a, 5b, 5c, 5d and 5e were listed in Table (2). Compound 5c revealed docking score -6.018386 with energy score (S) $45.487493 \mathrm{kcal} / \mathrm{mol}$ and interacted with ARG 84 with hydrogen bonds through $\mathrm{NO}_{2}$ of the phenyl moiety (Fig. 3). Compound 5d showed the docking score -6.064761 with energy score (S) $-43.744902 \mathrm{kcal} / \mathrm{mol}$ and interacted with ASN 54 with a hydrogen bond through a $\mathrm{N}-\mathrm{H}$ of the Azetidinone ring (Fig.3). Apart from hydrogen bonding, hydrophobic and van der Waals interactions were also detected between lead molecule 5a, 5b and 5e with DNA gyrase. The entire synthesized azetidinone derivatives were projected into the hydrophobic pocket of DNA gyrase defined by LEU 103, VAL 131, 79 \& 130, ILE 51, 86, $102 \&$ 175, THR 173,SER 55, \& 129, ASP 81, ASN 54, GLU 58, GLY 83 \& 85, PRO 87 and ARG 84 \& 144 amino acid residues of the target protein (Fig.3).

From the docking study we predicted that Azetidinone analogues (5a, 5b, 5c, 5d and 5e) possess better antibacterial activity by having good binding affinity with target protein and it could be used as potential drugs as antimicrobial. Amongst all the docked compounds, the compound (5b) shows good binding affinity \& interaction docking score of -6.4676 with DNA gyrase enzymes with reference to ciprofloxacin shown in figure 3.

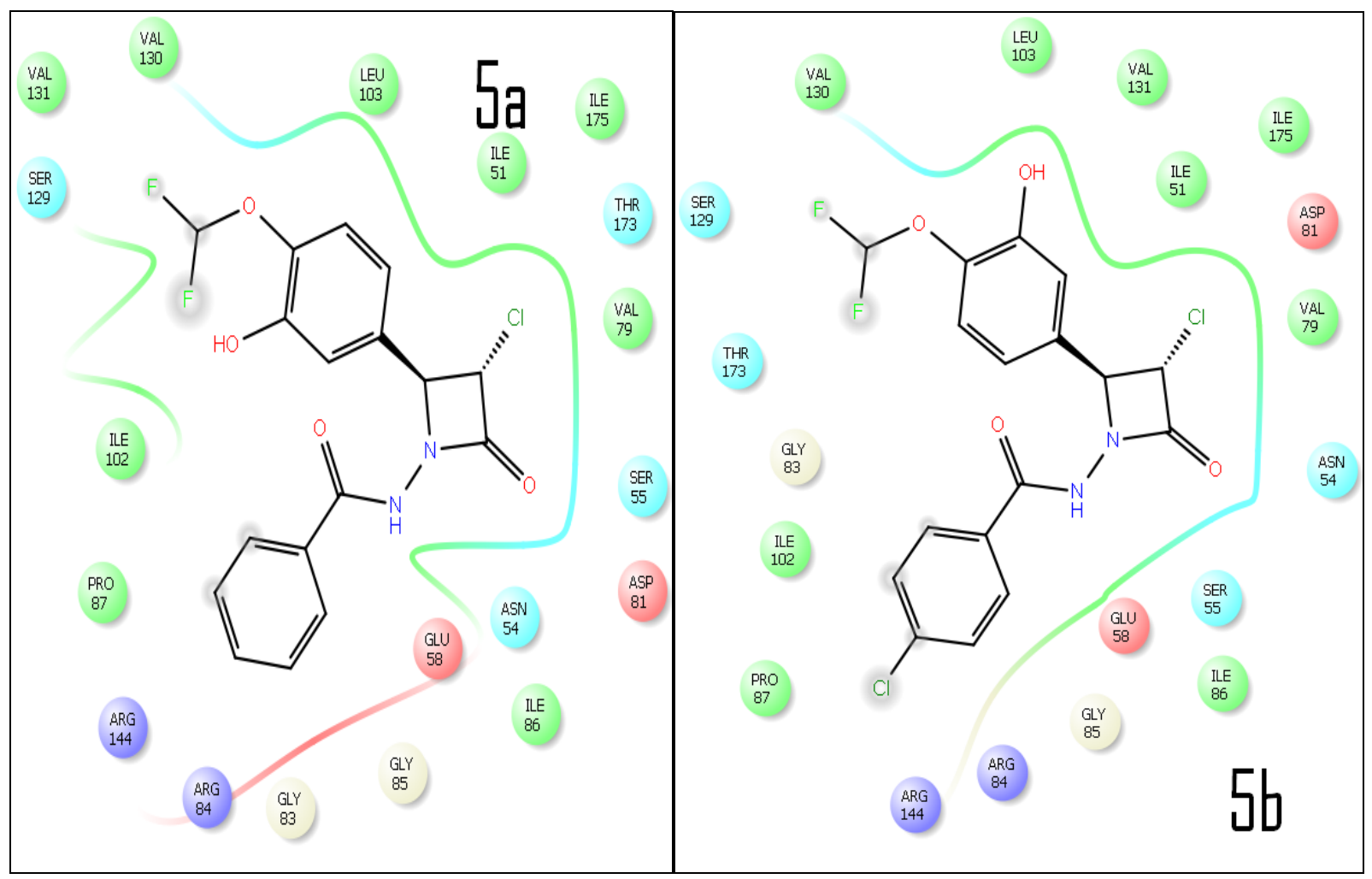




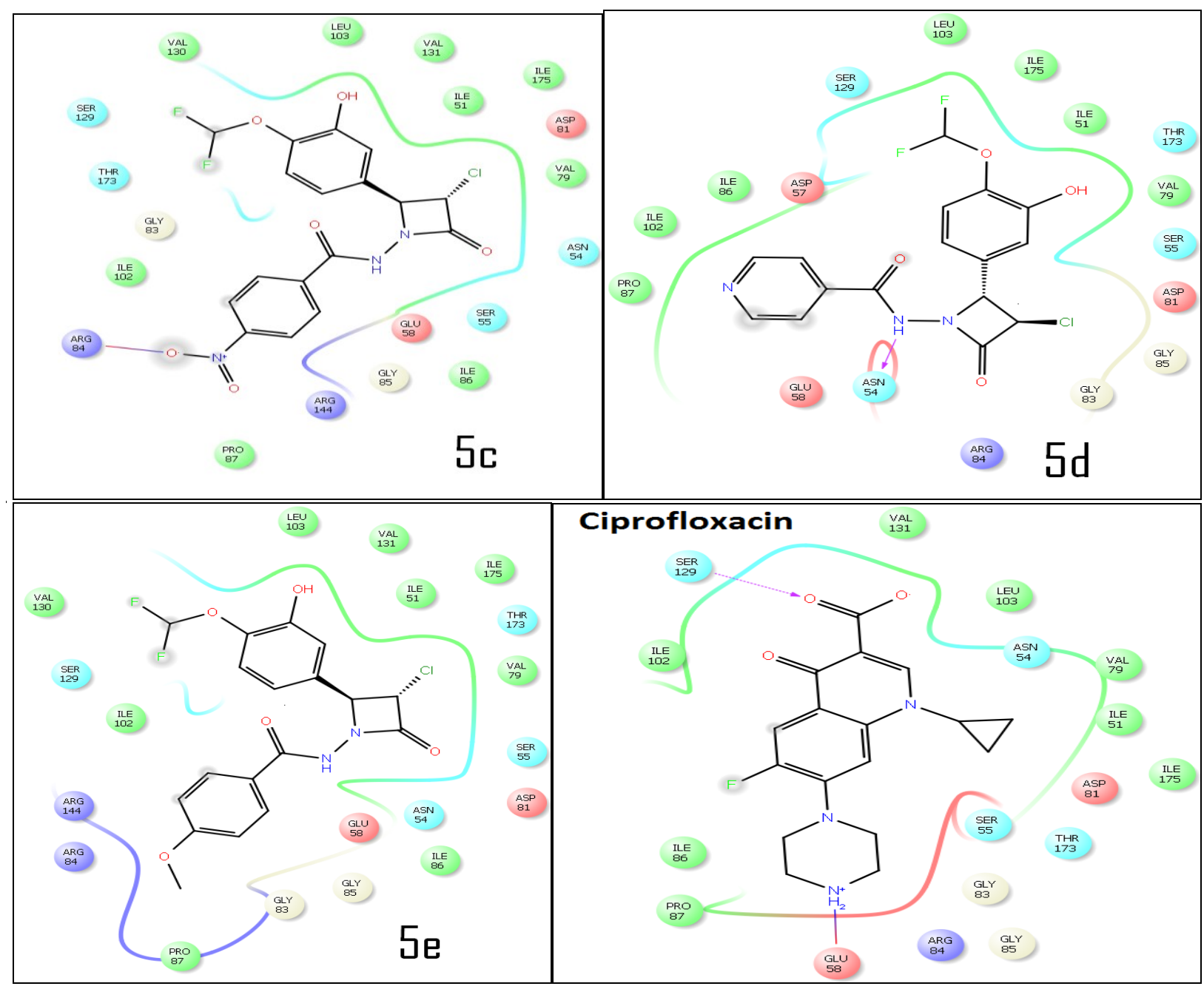

Figure 3. Binding conformation and interaction of ligands 5a, 5b, 5c, 5d 5e and standard ciprofloxacin within the active site of DNA Gyrase.

\subsection{ANTIBACTERIAL ACTIVITY}

All the synthesized compounds were evaluated in vitro for antibacterial activity by using filter paper disc method(E.W. Koneman et al, 1997; V. Cleidson et al, 2007) against different strains of bacteria viz. B. substilis, E. coli, S. aureus Pseudomonas aeruginosa and Streptococcus pyogenes. All the compounds along with standard antibacterial Ciprofloxacin were used at $150 \mu \mathrm{g}$ concentrations. Nutrient agar medium was used for the study. After sterilization the nutrient agar medium was melted, cooled and inoculated with three Gram-positive organisms $S$. aureus, B. subtilis, Streptococcus pyogenes and two Gram-negative organisms E. coli, P. aeruginosa and poured into sterile Petri dish to get a uniform thickness of $6 \mathrm{~mm}$. Dried and sterilized filter paper discs $(6 \mathrm{~mm}$ in diameter) soaked with known amount of test agents were placed on the nutrient agar media solidified in petridishes .The standard antibacterial agent Ciprofloxacin $(150 \mu \mathrm{g})$, solvent control and the synthesized compounds in a concentration of 150 
$\mu \mathrm{g}$ were The plates were then incubated at $37^{\circ} \mathrm{C}$ for $24 \mathrm{~h}$ and the diameter of zone of inhibition were measured and recorded in Table 3.

The zone of inhibition of all compounds is presented in Table 1 and Figure 8. Ciprofloxacin was used as standard drug for comparison with test compounds. All the tested compounds showed good antibacterial activity against Gram-positive and gram-negative strains. Among tested compounds, $5 \mathrm{~b}$ showed significant zone at $16 \mathrm{~mm}$ and $15 \mathrm{~mm}$ against $\mathrm{B}$. subtilis and S. aureus, respectively and found moderate active against both Gram-negative strains E. coli $(13 \mathrm{~mm})$ and $\mathrm{P}$. aeruginosa $(16 \mathrm{~mm})$. Compound possessing electron withdrawing chloro group (5a) showed moderate activity against both Gram-positive bacteria when compared to other derivatives in the series (Table 3 ). All other derivatives shown moderate to good activity against bacterial strains.
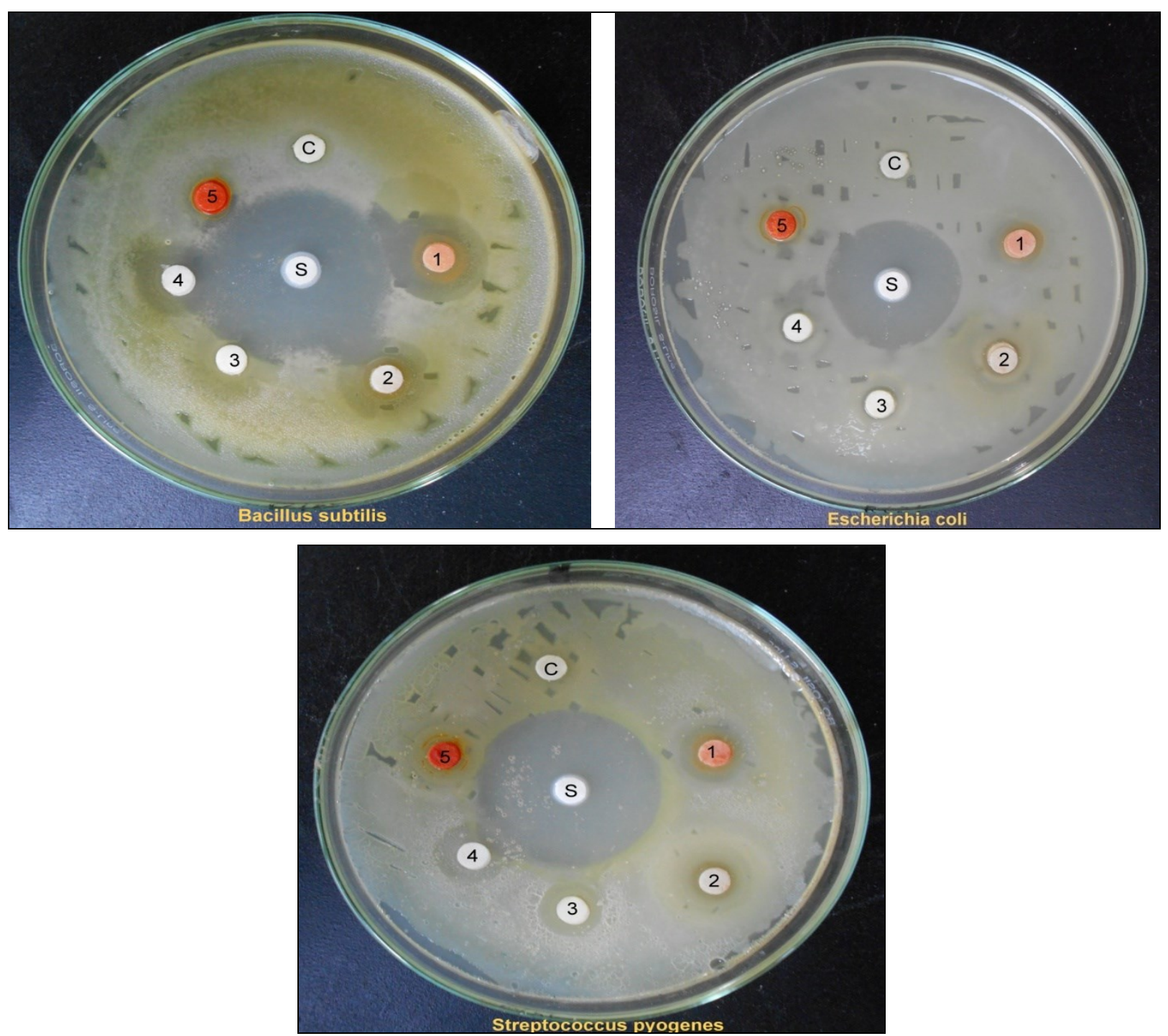


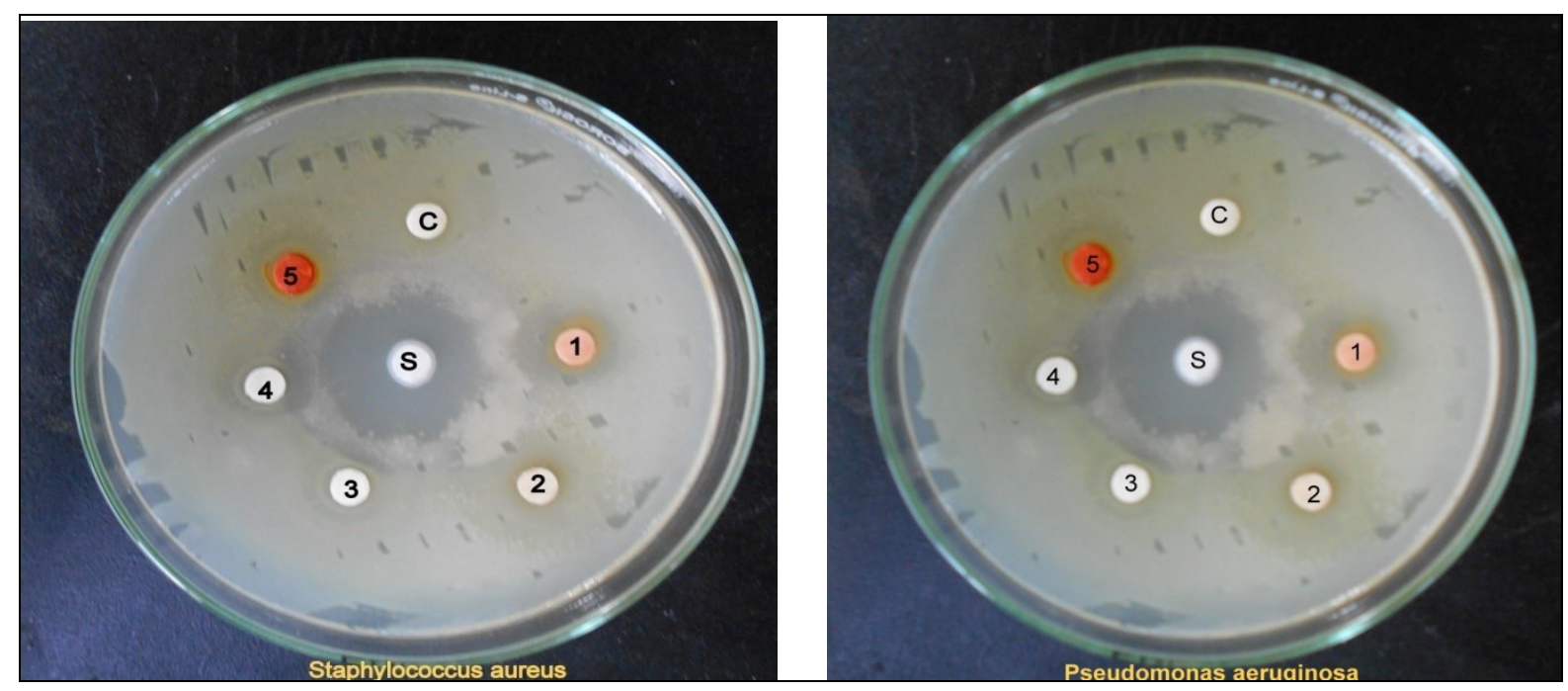

Figure 4. In vitro antibacterial activity of synthesized azetidinone compounds 5a-e.

Table 3. Antibacterial activity.

\begin{tabular}{|c|c|c|c|c|c|c|c|}
\hline \multirow{2}{*}{ S. No. } & \multirow{2}{*}{ Bacteria } & \multirow{2}{*}{$\begin{array}{c}\text { Standard } \\
\text { Antibiotic } \\
\text { Disk* }\end{array}$} & \multirow{4}{|c|}{ Zone of inhibition mm in diameter } \\
\cline { 4 - 8 } & & 1 & 2 & 3 & 4 & 5 \\
\cline { 4 - 8 } & & $5 \mathrm{a}$ & $5 \mathrm{~b}$ & $5 \mathrm{c}$ & $5 \mathrm{~d}$ & $5 \mathrm{e}$ \\
\hline 1 & Bacillus subtilis & 24 & 18 & 16 & 16 & 15 & 12 \\
\hline 2 & Escherichia coli & 18 & 10 & 13 & 08 & 12 & 10 \\
3 & Pseudomonas aeruginosa & 16 & 13 & 16 & 13 & 14 & 14 \\
\hline 5 & Staphylococcus aureus & 18 & 13 & 15 & 12 & 13 & 12 \\
\hline 5 & Streptococcus pyogenes & 28 & 12 & 16 & 14 & 15 & 16 \\
\hline
\end{tabular}

*Ciprofloxacin

\subsection{CONCLUSION}

A series substituted N-(3-chloro-2-(4-(difluoromethoxy)-3-hydroxyphenyl)-4-oxoazetidin1-yl) derivatives benzamide (5a-e) were synthesized in good yields and were evaluated for antibacterial activities. Docking studies has been carried out by using Maestro 9.3 software for all the derivatives. The structures of the synthesized compounds were confirmed by FT-IR, 1H NMR spectral analysis. All the derivatives of 5a-e were docked with target protein for DNA Gyrase to predict the antibacterial activity. The results of the docking study for all the derivatives are shown in table. Amongst all the docked compounds, the compound (5b) shows good binding affinity \& interaction docking score of -6.4676 with DNA gyrase enzymes with reference to 
ciprofloxacin. The pharmacological study was undertaken to evaluate the effects of substituents on the antibacterial activity. All the synthesized compounds exhibited good antibacterial activity towards Gram-positive bacteria and gram negative bacteria strains. The theoretical results obtained in the molecular docking were compared with the experimental results. The theoretical results obtained after docking of azetidinone analogues with DNA gyrace showed good agreement with the experimental results. Thus it confirms that, the experimental values moderately agree with theoretical values, which suggest that the parameters for docking simulation are optimum in reproducing experimental orientation of these compounds.

\section{References}

[1] Sumit Bansal et al., Design, Synthesis, Docking Study \& Antibacterial Evaluation of 1,3Diarylpyrazolyl Substituted Indolin-2-ones, Indo Global Journal of Pharmaceutical Sciences, 2014; 4(1): 1-7

[2] Kilarimath Basavaraj et al., Synthesis, Docking and Antitubercular Activity of some newer Azetidinones, Unique journal of pharmaceutical and biological sciences, 2014, 02 (01); 4350

[3] Sharma et al., N/C-4 substituted azetidin-2-ones: Synthesis and preliminary evaluation as new class of antimicrobial agents, Bioorg. Med. Chem. Lett. 2007, 17, 341-345.

[4] Gurupadayya B M et al., Synthesis and Pharmacological Evaluation of Azetidin- 2-ones and Thiazolidin-4-ones Encompassing Benzothiazole, Indian J. Pharm. Sci. 2008, 70 (5), 572577.

[5] Rajasekaran, A., Murugesan, S, Synthesis and characterization of some novel azetidinone derivatives as anti-bacterial and anti-convulsant agents, J. Pharm. Bioresour. 20052 (2), $162-168$.

[6] Rosenblum, S.B., Huynh, T., Afonso, A., Davis H.R., Synthesis of 3-arylpropenyl, 3arylpropynyl and 3-arylpropyl 2- azetidinones as cholesterol absorption inhibitors: application of the palladium-catalyzed arylation of alkenes and alkynes. Tetrahedron ., 2000. $56,5735-5742$.

[7] Jyotsna Meshram et al, Microwave Mediated Cyclocondensation of 2-aminothiazole into $\beta$ lactam Derivatives: Virtual Screening and In Vitro Antimicrobial Activity with Various Microorganisms, Int.J. ChemTech Res.2010,2(2),231-237

[8] Smita pawar et al., Synthesis of novel antimicrobial derivatives of 3-substituted pyrrolidine2, 5-diones using pharmacophore hybrid approach: part-I, Int J Pharm Pharm Sci,2014, 6(2), 486-490

[9] Amit Poshiya et al, Synthesis studies of bacterial dna-gyrase inhibitors, IJPT, 2011 3(3)| 3048-3059

[10] E.W. Koneman, S.D. Allen, W.M. Janda, P.C. Schreckenberger, Colour Atlas and Text Book of Diagnostic Microbiology, 5th ed., Jt. Editor W.C. Winn, Lippincott, Philadelphia, P.A., 1997,185 . 
[11] V. Cleidson, M. Simone, F.A.S. Elza Artur S. Jr., Braz. J.microbiol., 2007, 38(2), 369-380.

[12] Daisy P, Vijayalakshmi P, Selvaraj C, Singh SK, Saipriya K. Targeting Multidrug Resistant Mycobacterium Tuberculosis Htra2 With Identical Chemical Entities Of Fluoroquinolones, Indian Journal Of Pharmaceutical Sciences 2012; 74(3): 189-280

[13] Pandurangan Perumal et al., Docking Studies on Some Novel Piperidine Analogues Against DNA Gyrase Enzyme., Inventi Rapid: Molecular Modeling 2014, 1, 256-260 